\title{
UNIVERSIDADE NA AMÉRICA LATINA: FUNDAMENTOS DA INTEGRAÇÃO E REDES DE CONHECIMENTO
}

\author{
UNIVERSITY IN LATIN AMERICA: FUNDAMENTALS OF INTEGRATION AND \\ KNOWLEDGE NETWORKS
}

\section{UNIVERSIDAD EN AMÉRICA LATINA: FUNDAMENTOS DE LA INTEGRACIÓN Y REDES DE CONOCIMIENTO}

\author{
Célio da Cunha \\ E-mail: celio.cunha@gmail.com \\ Universidade Católica de Brasília
}

\begin{abstract}
RESUMO
Uma das direções temáticas proposta para esse painel sobre redes de investigação refere-se à integração acadêmica e solidária da região e sua importância nos processos de formulação de políticas públicas e tomadas de decisões na educação superior. Trata-se de um tema que pode ser abordado por diversos ângulos. Com o objetivo de oferecer não mais do que alguns subsídios, farei inicialmente uma abordagem do contexto social, econômico e cultural da América Latina, pois as redes de investigação precisam ter um sentido construído e sedimentado considerando os delineamentos históricos e culturais, como também os impasses e dilemas da região. Para tanto, utilizarei, entre outros documentos e fontes, o Estudo Comparativo dos Sistemas Educacionais dos Países da Unasul, elaborado sob minha coordenação, em 2015.
\end{abstract}

PALAVRAS-CHAVE: Redes de investigação. Integração acadêmica. América Latina.

\section{ABSTRACT}

One of the proposed thematic directorates for this panel on research networks refers to the academic and solidarity integration of the region and its importance in the processes of public policy making and decision making in higher education. It is a theme that can be approached from several angles. With the objective of offering no more than a few subsidies, I will initially approach the social, economic and cultural context of Latin America, since research networks need to have a constructed and settled sense considering historical and cultural delineations, as well as impasses and dilemmas of the region. To do so, I will use, among other documents and sources, the Comparative Study of Educational Systems of the Countries of Unasur, prepared under my coordination, in 2015.

KEYWORDS: Research networks. Academic Integration. Latin America.

\section{RESUMEN}

Una de las direcciones temáticas propuesta para ese panel sobre redes de investigación se refiere a la integración académica y solidaria de la región y su importancia en los procesos de formulación de políticas públicas y toma de decisiones en la educación superior. Se trata de un tema que puede ser abordado por diversos ángulos. Con el objetivo de ofrecer no más que algunos subsidios, haré inicialmente un abordaje del contexto social, económico y cultural de América Latina, pues las redes de investigación necesitan tener un sentido construido y sedimentado considerando los delineamientos históricos y culturales, así como los impasses y dilemas de la región. Para ello, utilizaré, entre otros documentos y fuentes, el Estudio Comparativo de los Sistemas Educativos de los Países de la Unasur, elaborado bajo mi coordinación, en 2015.

PALABRAS-CLAVE: Redes de investigación. Integración Académica. América Latina. 


\section{INTRODUÇÃO: a relevância do contexto}

Estudos mais recentes sobre políticas de educação e educação comparada acentuam a importância do conhecimento do contexto em suas múltiplas dimensões - históricas, econômicas e socioculturais. Trata-se de uma condição prévia que pode favorecer a formulação de projetos e programas de acordo com as reais necessidades de um país ou de uma região. Sob esse aspecto, tem razão Sonia Mehta quando afirma que muitas críticas oriundas das ciências sociais apontaram que os iluministas do chamado Século das Luzes, com toda sua elegância e promessas da razão e da ideologia humanitária, moldaram uma sociedade hostil às diferenças, à diversidade e às culturas não ocidentais, vistas como culturas do conhecimento não científico (MEHTA, 2012, p. 650). Como a escola de hoje tem, em boa parte, suas raízes no Iluminismo, período da história em que a proeminência da razão chegou ao zênite, os conhecimentos gerados por outras vias e itinerários que não aqueles obtidos pela ciência, acabaram ficando em segundo plano, mesmo considerando sua importância para a construção de identidades, como também para o desenvolvimento social e econômico. Como salientou Mehta (2012), o privilégio atribuído à verdade científica acima de todas as outras, limita as opções epistemológicas e a compreensão integral da diversidade humana. Ocorre que, mediante o avanço do conhecimento em suas diferentes divisões, seguido pelo avanço dos direitos humanos, além de outros fatores políticos, econômicos e sociais, o século XXI, isto é, o atual milênio, tende a configurar-se cada vez mais como o século da universalização de condições mínimas de vida digna. Por tais razões, vozes antes emudecidas por lógicas hegemônicas do pensamento, lutam para fazer parte do discurso dominante. Mais do que isso. Múltiplos olhares e vozes geram entendimento diferente do fato social. É crescente a discordância da naturalização do discurso monolítico do Iluminismo. Daí a atualidade de reflexões pós-modernistas da educação (MEHTA, 2012).

Nesse cenário, sobressai a relevância do estudo prévio do contexto. Lewin (apud CROSSLEY, 2012) argumentou que as metas estabelecidas por uma política de educação, podem ser prejudicadas por metas e alvos homogêneos e, por vezes, descontextualizados. "São os fatores contextuais e a consciência crescente sobre sua importância na pesquisa e na mudança educacional que dão sustentação a muitos dos principais desenvolvimentos de nosso tempo" (CROSSLEY, 2012, p. 633). Ademais, insiste esse pesquisador, que o póscolonialismo e o pós-modernismo têm em comum a crítica sobre a metateoria com orientação global e com base nos pressupostos do Iluminismo. Ao chamar a atenção para os contextos 
políticos e intelectuais da produção e da legitimação do conhecimento, os pesquisadores começam a focalizar a desconstrução dos pontos de vista dominantes sobre o mundo, e a explorar a relação entre política, conhecimento e poder (CROSSLEY, 2012, p. 635).

\section{Legado da Colonização}

Tais pressupostos sobre a necessidade de consideração dos contextos, em suas múltiplas variáveis, assumem importância nada desprezível para repensar o futuro da América Latina, pois a política de colonização, como lembrou Rojas Mix, teve a função de marginalizar ou mesmo apagar a cultura original das nações que habitavam a América. Colonizados por séculos, tiveram que aprehender un nuevo espacio para representar al mundo, un espacio donde el dominio de la perspectiva europea los obligaba a negar el tiempo y a sacrificar la historia (...) (MIX, 2004, p. 34). Felizmente, o avanço das ciências e das abordagens interdisciplinares do conhecimento está permitindo a abertura de novos espaços de análises e interpretações que começam a ter implicações na formulação de políticas públicas de desenvolvimento humano e valorização da vida.

Mais recentemente e na mesma linha de Mix, parece-me oportuno trazer para a mesa de debates, os argumentos de Francisco Bethencourt que escreveu uma admirável obra sobre os racismos desde o tempo das Cruzadas.

Nos países americanos ibéricos independentes como o Brasil, salientou esse pesquisador, a política de atração dos migrantes europeus, que chegavam cada vez em maior número após a abolição da escravatura, foi explicitamente definida como sendo um projeto para embranquecer a população (BETHENCOURT, 2015, p. 325).

Assinalou ainda, a propósito do debate sobre a escravidão nos Estados Unidos, os efeitos sobre a teorização científica acerca da raça, mostrando como os interesses políticos prementes podiam interferir com novos campos de conhecimento, sobretudo a classificação das espécies, destacando que o preconceito racial e as ações discriminatórias se beneficiaram com esse apoio científico, de forma a prolongar o debate sobre as práticas escravagistas (p. 328-329). Afirmou que a pesquisa científica sobre a variedade de seres humanos se tornou muito mais assertiva, ideologicamente agressiva e politicamente empenhada. Esta nova etapa do desenvolvimento, sobretudo a partir das décadas de 1840 e 1850, Bethencourt a denominou de racialismo científico, pois ele trouxe consigo um esforço científico para justificar e reificar as divisões bem como as hierarquias de raças, que supostamente seriam

\begin{tabular}{l|l|l|l|l|l|} 
(C) Revista Triangulo & Uberaba, Minas Gerais & v.11 & n.4 - Esp & p. 7-26 & 2018
\end{tabular}


inatas, imutáveis e perpétuas (p. 363), o que contribuiu para o fortalecimento da "ideologia do colonialismo", que é o título de uma obra clássica de Nelson Werneck Sodré.

Assim sendo, e para repetir mais uma vez o argumento clássico de M. Sadler, um dos pioneiros da educação comparada, de que as mudas recolhidas de outros contextos não se transformarão ipso facto em plantas vivas quando forem transportadas, porém admitindo que uma planta morta carrega micro-organismos que podem alterar um ecossistema (SADLER, 1900). Certamente muitas dessas plantas transplantadas para as terras que Colombo pensava que fosse a Índia, alteraram e obliteraram concepções e modos de vida das inúmeras nações que habitavam o novo mundo. Desse argumento deriva a necessidade de conhecer um pouco mais da cultura e da situação social e econômica do continente, requisito indispensável para o delineamento de horizontes mais claros que venham a facilitar a construção de políticas públicas amplamente inclusivas e respeitadoras dos saberes e dos modos de ser construídos ao longo da história das diversas nações.

\section{Contexto social e econômico: antecedentes}

Constitui tarefa das mais complexas sintetizar uma visão global sobre a situação econômica e social da América Latina, devido à diversidade de situações e de cenários, como também das diferenças existentes, sobretudo, das diferenças entre o Brasil, de colonização portuguesa, das nações de língua espanhola e da Guiana de língua inglesa. Em que pese essa diversidade de cenários, existem também questões comuns que derivam do impulso que tomou o fenômeno da globalização nos últimos decênios do século $\mathrm{XX}$, provocando $\mathrm{e}$ promovendo transformações que haveriam de afetar a vida das nações em escala mundial. Para o novo cenário de radical globalização, certamente contribuíram os notáveis avanços da ciência e da tecnologia após a Segunda Guerra, com especial destaque para as ciências da informação e da comunicação, que operaram a revolução de colocar em circuito instantâneo de diálogo e intercâmbio os negócios, a sociedade e a cultura de países dos vários continentes, como também a queda do Muro de Berlim e a desagregação da União das Repúblicas Socialistas Soviéticas, em 1989, e a radicalização da política neoliberal liderada pelo Presidente Reagan, dos Estados Unidos da América e pela Primeira Ministra Margareth Thatcher, da Inglaterra, período em que as ideias de bem-estar social de Keynes cederam lugar para a visão estreita das políticas monetaristas. 


\section{A hegemonia dos pressupostos neoliberais}

Uma das consequências do domínio da ideologia neoliberal foi a fragilização do Estado. Fortaleceu-se, como observou Castro, a visão analítica e política de que o Estado, da forma como se encontrava estruturado na maioria dos países, representava um entrave ao desenvolvimento das forças produtivas e, por conseguinte, precisava ser reformado, ou seja, o Estado tornara-se obstáculo ao processo de acumulação. Em decorrência, os postulados neokeynesianos foram deixados de lado em favor dos princípios liberais da economia (CASTRO, 2012).

A instauração de um novo quadro da economia mundial presidido pela doutrina do neoliberalismo, por um lado, fragilizou o poder do Estado nacional e, por outro, fortaleceu o setor privado. Em consequência, ganhou forças renovadas a desregulamentação do mercado e a política de privatizações. A nova orientação, salientou Castro, haveria de ter no Consenso de Washington a sua formalização maior, que passou a orientar e servir de referência para os empréstimos, principalmente, junto ao Fundo Monetário Internacional (FMI), fortalecendo a concepção, entre investidores e lideranças políticas, de que a aplicação da receita neoliberal era inexorável, em especial para aqueles países com modelos de desenvolvimento marcados por forte intervenção estatal (CASTRO, 2012).

Àquele tempo (década de 1980), o poder das ideias neoliberais era muito forte, o que concorreu para que vários países latino-americanos empreendessem reformas nessa linha de pensamento, com a esperança de obterem resultados mais expressivos nas políticas de desenvolvimento econômico e social. Todavia, como salientou Castro, as expectativas não se confirmaram. Em que pesem ganhos obtidos no controle da inflação ou na diversificação das exportações, as políticas ortodoxas não conseguiram equilibrar as contas públicas da maioria dos países da região, uma vez que o processo de estabilização foi fortemente sustentado pela emissão de títulos públicos de elevada rentabilidade. Mesmo os países mais desenvolvidos da região tiveram de continuar dependentes de capitais externos, como ainda de importações indispensáveis à modernização dos setores produtivos (CASTRO, 2012). Decorridos alguns anos de vigência dessa política, os resultados esperados não se efetivaram.

Com a não concretização dos resultados esperados e da crença no ideário neoliberal, os países da região sentiram a necessidade de empreenderem mudanças na economia, mediante a busca de alternativas que pudessem gerar maior equilíbrio entre os fundamentos sociais do Estado e a dimensão econômica do mercado. Estudiosos e pesquisadores de 
diversas universidades e centros de pesquisa, há muito vinham alertando para os limites do modelo neoliberal de desenvolvimento, sobretudo em termos de inclusão social e de emprego. Um desses estudiosos do desenvolvimento humano, Amartya Sen, teceu críticas às limitações da perspectiva utilitarista, responsável pela indiferença distributiva, na medida em que o cálculo utilitarista tende a não levar em consideração as desigualdades na distribuição do bem-estar, importando apenas a soma total, independentemente do quanto sua distribuição seja desigual (SEN, 2000, p. 81). Nessa mesma lógica, sublinham-se os esforços de Anthony Guiddens em direção a uma "terceira via". Como ele mesmo afirmou, a política de "terceira via" surgiu diante de uma dupla crise política. Por um lado, o declínio do bloco soviético, em 1989, mostrou que o socialismo não era um caminho viável para a organização econômica; por outro, o entusiasmo irreprimido em relação ao livre mercado, que tinha a preferência dos neoliberais conservadores, também havia falhado. A "terceira via" concebeu uma nova economia mista caracterizada por um equilíbrio entre a regulamentação e a desregulamentação do governo. Ela rejeita a visão neoliberal de que a desregulamentação seja o único caminho para assegurar a liberdade e o crescimento (GUIDDENS, 2001, p. 355-356). Todavia, as ideias de Sen, Guiddens e de tantos outros pensadores que acreditavam na possibilidade de alternativas não foram ouvidas nas esferas hegemônicas do poder. No caso da América Latina, os países, em maior ou menor grau, reagiram e tentaram, ao menos, promover algum tipo de equilíbrio entre as políticas de estado liberais e as sociais.

\section{Reação ao ciclo neoliberal}

O outono da radicalização do ciclo neoliberal foi marcado por crise econômica e social na maior parte dos países da região. Os sucessivos abalos financeiros que assolaram o continente, no período de 1994 a 2003, colocaram por terra as ilusões do "Consenso de Washington". Ataques especulativos contra as moedas, crise nos balanços de pagamento, fuga de capitais e moratória das dívidas, estão entre alguns efeitos que acirraram os movimentos sociais de vários países. Grande parte da população foi às ruas para cobrar dívidas históricas, como o racismo contra os indígenas e afrodescendentes (PAULINO; PIRES, 2012, p. 407). Como consequência, após se esgotarem as alternativas tradicionais, ascenderam ao poder, em vários países, partidos políticos mais à esquerda, elegendo governantes oriundos dos movimentos sociais, como Michele Bachelet, no Chile, Luiz Inácio Lula da Silva, no Brasil, Alan Garcia, no Peru, Tabaré Vasquez ou José Mujica, no Uruguai, Evo Moralez, na Bolívia, 
Rafael Correa, no Equador, Fernando Lugo, no Paraguai e o casal Kirchner, na Argentina. Entretanto, por falta de maioria parlamentar, os novos governantes tiveram de ceder em muitas aspirações e objetivos. Malgrado essa limitação, avanços sociais reconhecidos por vários estudos tiveram lugar, sobretudo em relação à redução da pobreza (PAULINO; PIRES, 2012, p. 412).

Mais sensíveis ao desenvolvimento social, os novos governantes procuraram construir, por diversos caminhos, cenários humanos de maior justiça e equidade. No fundo, os esforços empreendidos assinalavam o desejo comum de projeção de horizontes futuros mais promissores. É certo que a crise de 2008, iniciada em Wall Street, teve efeitos mundiais, atingindo, por conseguinte, a América Latina. Como argumentam Paulino e Pires (2012), as oportunidades se abrem e depois de certo tempo se fecham. Coreia do Sul, Hong Kong e Cingapura souberam aproveitá-las na década de 1970, como também a China na década de 1990. É certo também que a América Latina soube aproveitar o ciclo virtuoso da economia mundial, alcançando resultados significativos em termos de controle da inflação, melhoria da infraestrutura e redução da pobreza. Todavia, perdeu muitas oportunidades no sentido de preparar suas economias para o enfrentamento de crises, como a de 2008.

O quadro 1 que segue, sobre alguns indicadores socioeconômicos da América Latina no período 2000-2013, mostra alguns dos avanços alcançados em relação ao PIB per capita, desemprego, salário médio real e índice de preços ao consumidor.

\section{Cuadro 1}

América Latina (20 países): evolución de algunos indicadores socioeconómicos, 20002013 (En porcentajes)

\begin{tabular}{|c|c|c|c|c|}
\hline \multirow{2}{*}{ País y año } & PIB per cápita & Desempleo & Salario medio real ${ }^{\mathrm{C}}$ & $\begin{array}{l}\text { Índice de precios } \\
\text { al consumidor }^{d}\end{array}$ \\
\hline & $\begin{array}{c}\text { (tasa media anual } \\
\text { de variación) }\end{array}$ & $\begin{array}{c}\text { (promedio simple } \\
\text { del período) }^{b}\end{array}$ & \multicolumn{2}{|c|}{ (tasa media anual de variación) } \\
\hline \multicolumn{5}{|l|}{ Argentina } \\
\hline $2000-2010$ & 2,4 & 12,5 & 5,2 & 9,1 \\
\hline 2011 & 7,6 & 7,2 & $\ldots$ & 9,5 \\
\hline 2012 & 0,1 & 7,2 & $\ldots$ & 10,8 \\
\hline 2013 & 2,1 & 7,1 & $\ldots$ & 10,9 \\
\hline \multicolumn{5}{|c|}{ Bolivia (Estado Plurinacional de) } \\
\hline $2000-2010$ & 1,9 & 7,6 & $-0,5$ & 5,0 \\
\hline 2011 & 3,6 & $\ldots$ & $-1,3$ & 6,9 \\
\hline 2012 & 3,6 & $\ldots$ & 0,9 & 4,5 \\
\hline 2013 & 5,2 & $\ldots$ & $\ldots$ & 6,5 \\
\hline
\end{tabular}


Revista Triângulo

ISSN 2175-1609

Cuadro I.1 (continuación)

\begin{tabular}{|c|c|c|c|c|}
\hline \multirow{2}{*}{ País y año } & PIB per cápita & Desempleo & Salario medio real ${ }^{\mathrm{C}}$ & $\begin{array}{l}\text { Índice de precios } \\
\text { al consumidor }^{d}\end{array}$ \\
\hline & $\begin{array}{c}\text { (tasa media anual } \\
\text { de variación) }\end{array}$ & $\begin{array}{c}\text { (promedio simple } \\
\text { del período)b }\end{array}$ & \multicolumn{2}{|c|}{ (tasa media anual de variación) } \\
\hline \multicolumn{5}{|l|}{ Brasil } \\
\hline $2000-2010$ & 2,5 & 9,1 & $-0,6$ & 6,6 \\
\hline 2011 & 1,9 & 6,0 & 2,4 & 6,5 \\
\hline 2012 & 0,2 & 5,5 & 3,7 & 5,8 \\
\hline 2013 & 1,7 & 5,4 & 1,1 & 5,9 \\
\hline \multicolumn{5}{|l|}{ Chile } \\
\hline $2000-2010$ & 2,8 & 9,0 & 1,9 & 3,3 \\
\hline 2011 & 4,9 & 7,1 & 2,5 & 4,4 \\
\hline 2012 & 4,5 & 6,4 & 3,2 & 1,5 \\
\hline 2013 & 3,2 & 5,9 & 3,9 & 3,1 \\
\hline \multicolumn{5}{|l|}{ Colombia } \\
\hline $2000-2010$ & 2,4 & 14,6 & 1,4 & 5,7 \\
\hline 2011 & 5,1 & 11,5 & 9,2 & 3,7 \\
\hline 2012 & 2,6 & 11,2 & $-7,2$ & 2,4 \\
\hline 2013 & 3,3 & 10,6 & 2,6 & 1,9 \\
\hline \multicolumn{5}{|l|}{ Costa Rica } \\
\hline $2000-2010$ & 2,3 & 6,2 & 1,1 & 10,1 \\
\hline 2011 & 3,1 & 7,7 & 5,7 & 4,7 \\
\hline 2012 & 3,7 & 7,8 & 1,4 & 4,5 \\
\hline 2013 & 2,2 & 8,2 & 1,3 & 3,7 \\
\hline \multicolumn{5}{|l|}{ Cuba } \\
\hline $2000-2010$ & 5,1 & 2,6 & 4,8 & 2,6 \\
\hline 2011 & 2,8 & 3,2 & 0,3 & 1,3 \\
\hline 2012 & 3,0 & 3,5 & 0,3 & 2,0 \\
\hline 2013 & 2,7 & $\ldots$ & $\ldots$ & 0,04 \\
\hline \multicolumn{5}{|l|}{ Ecuador } \\
\hline $2000-2010$ & 2,0 & 8,8 & $\ldots$ & 12,2 \\
\hline 2011 & 6,0 & 6,0 & $\ldots$ & 5,4 \\
\hline 2012 & 3,4 & 4,9 & $\ldots$ & 4,2 \\
\hline 2013 & 2,8 & 4,7 & $\ldots$ & 2,7 \\
\hline \multicolumn{5}{|l|}{ El Salvador } \\
\hline $2000-2010$ & 1,5 & 6,4 & $-1,3$ & 3,4 \\
\hline 2011 & 1,7 & 6,6 & $-2,9$ & 5,1 \\
\hline 2012 & 1,3 & 6,2 & 0,2 & 0,8 \\
\hline 2013 & 1,1 & $\ldots$ & 0,5 & 0,8 \\
\hline \multicolumn{5}{|l|}{ Guatemala } \\
\hline $2000-2010$ & 0,9 & 4,9 & $-0,5$ & 6,6 \\
\hline 2011 & 1,7 & 3,1 & 0,4 & 6,2 \\
\hline 2012 & 0,5 & 4,0 & 4,0 & 3,4 \\
\hline 2013 & 1,2 & 3,8 & $-0,2$ & 4,4 \\
\hline \multicolumn{5}{|l|}{ Haití } \\
\hline $2000-2010$ & $-1,3$ & $\ldots$ & $\ldots$ & 13,6 \\
\hline 2011 & 4,2 & $\ldots$ & $\ldots$ & 8,3 \\
\hline 2012 & 1,6 & $\ldots$ & $\ldots$ & 7,6 \\
\hline 2013 & 3,0 & $\ldots$ & $\ldots$ & 3,4 \\
\hline \multicolumn{5}{|l|}{ Honduras } \\
\hline $2000-2010$ & 2,2 & 5,7 & $\ldots$ & 7,7 \\
\hline 2011 & 1,8 & 6,8 & $\ldots$ & 5,6 \\
\hline 2012 & 1,9 & 5,6 & $\ldots$ & 5,4 \\
\hline 2013 & 0,6 & 6,0 & $\ldots$ & 4,9 \\
\hline \multicolumn{5}{|l|}{ México } \\
\hline $2000-2010$ & 1,0 & 4,2 & 2,0 & 4,9 \\
\hline 2011 & 2,7 & 5,9 & 0,9 & 3,8 \\
\hline 2012 & 2,8 & 5,8 & 0,2 & 3,6 \\
\hline 2013 & $-0,1$ & 5,7 & $-0,1$ & 4,0 \\
\hline \multicolumn{5}{|l|}{ Nicaragua } \\
\hline $2000-2010$ & 1,6 & 9,0 & 0,7 & 9,3 \\
\hline 2011 & 4,2 & $\ldots$ & 0,1 & 8,6 \\
\hline 2012 & 3,5 & $\ldots$ & 0,4 & 7,1 \\
\hline 2013 & 3,1 & $\ldots$ & 0,3 & 5,4 \\
\hline
\end{tabular}




\begin{tabular}{|c|c|c|c|c|}
\hline \multirow{2}{*}{ País y año } & PIB per cápita & Desempleo & Salario medio real ${ }^{c}$ & $\begin{array}{l}\text { Índice de precios } \\
\text { al consumidor }\end{array}$ \\
\hline & $\begin{array}{l}\text { (tasa media anual } \\
\text { de variación) }\end{array}$ & $\begin{array}{l}\text { (promedio simple } \\
\text { del período) }\end{array}$ & \multicolumn{2}{|c|}{ (tasa media anual de variación) } \\
\hline \multicolumn{5}{|l|}{ Panamá } \\
\hline $2000-2010$ & 3,8 & 11,9 & $-0,3$ & 2,6 \\
\hline 2011 & 8,9 & 5,4 & 0,1 & 6,3 \\
\hline 2012 & 8,4 & 4,8 & 3,4 & 4,6 \\
\hline 2013 & 6,6 & 4,7 & 1,8 & 3,7 \\
\hline \multicolumn{5}{|l|}{ Paraguay } \\
\hline $2000-2010$ & 1,0 & 9,4 & 0,6 & 8,0 \\
\hline 2011 & 2,6 & 7,1 & 2,7 & 4,9 \\
\hline 2012 & $-2,8$ & 8,1 & 0,7 & 4,0 \\
\hline 2013 & 11,8 & 8,1 & 2,2 & 3,7 \\
\hline \multicolumn{5}{|l|}{ Perú } \\
\hline $2000-2010$ & 4,0 & 8,8 & 1,1 & 2,4 \\
\hline 2011 & 5,3 & 7.7 & $\ldots$ & 4,7 \\
\hline 2012 & 4,7 & 6,8 & $\ldots$ & 2,6 \\
\hline 2013 & 4,5 & 5,9 & $\ldots$ & 2,9 \\
\hline \multicolumn{5}{|c|}{ República Dominicana } \\
\hline $2000-2010$ & 3,8 & 6,6 & $\ldots$ & 11,6 \\
\hline 2011 & 3,1 & 5,8 & $\ldots$ & 7,8 \\
\hline 2012 & 2,6 & 6,5 & $\ldots$ & 3,9 \\
\hline 2013 & 2,8 & 7,0 & $\ldots$ & 3,9 \\
\hline \multicolumn{5}{|l|}{ Uruguay } \\
\hline $2000-2010$ & 2,7 & 12,1 & 0,1 & 8.4 \\
\hline 2011 & 7,0 & 6,6 & 4,0 & 8,6 \\
\hline 2012 & 3,3 & 6,7 & 4,2 & 7,5 \\
\hline 2013 & 4,0 & 6,7 & 3,0 & 8,5 \\
\hline \multicolumn{5}{|c|}{ Venezuela (República Bolivariana de) } \\
\hline $2000-2010$ & 1,4 & 11,9 & $-2,5$ & 21,6 \\
\hline 2011 & 2,6 & 8,3 & 3,0 & 27,6 \\
\hline 2012 & 4,0 & 8,1 & 5,8 & 20,1 \\
\hline 2013 & $-0,1$ & 7,8 & $-4,4$ & 56,2 \\
\hline \multicolumn{5}{|c|}{ América Latina ${ }^{\mathrm{e}}$} \\
\hline $2000-2010$ & 2,0 & 9,2 & $\ldots$ & 7,7 \\
\hline 2011 & 3,3 & 6,7 & $\ldots$ & 7,0 \\
\hline 2012 & 1,9 & 6,4 & $\ldots$ & 5,3 \\
\hline 2013 & 1,5 & 6,3 & $\ldots$ & 6,8 \\
\hline
\end{tabular}

Fuente: Comisión Económica para América Latina y el Caribe (CEPAL), sobre la base de cifras oficiales.
a Calculada sobre la base del valor del PIB per cápita en dólares, a precios constantes de 2005. El promedio de América Latina corresponde al promedio ponderado de las variaciones del PIB de los países de la subregión.

La información por países proviene de fuentes oficiales de carácter nacional. Para el período 2000-2010, solo se dispuso de datos de Guatemala del trienio $2002-$ 2004 y de 2010, y de datos de Honduras a partir de 2001. Los datos de desempleo del Perú corresponden a los de la ciudad de Lima.

Por lo general, la cobertura de este indice es muy parcial. En la mayoria de los paises se refiere solo a los trabajadores formales del sector industria.

Corresponde a la variación interanual, con diciembre como mes de referencia. El agregado regional corresponde al promedio simple de las variaciones de los países.

El promedio regional (ponderado) de desempleo corresponde a America Latina y el Caribe. Se calculó con información de 25 paises, incluidos los que se presentan

en el cuadro excepto Haití y además las Bahamas, Barbados, Belice, Jamaica, Suriname y Trinidad y Tabago, utilizando como ponderador las cifras de población en

edad de trabajar según las proyecciones que elabora el CELADE-División de Población de la CEPAL.

Malgrado essas conquistas, o panorama atual é de incertezas. Os gráficos I e II seguintes sobre a evolução da pobreza e da indigência, indicam um cenário de preocupações crescentes. São 167 milhões de pessoas pobres e 71 milhões de indigentes, sendo que de 2012 para 2013 pode ser observado um ligeiro aumento de pessoas indigentes.

\section{Gráficos 1 e 2}

América Latina: evolución de la pobreza y de la indigencia, 1980-2014

(En porcentajes y millones de personas) 

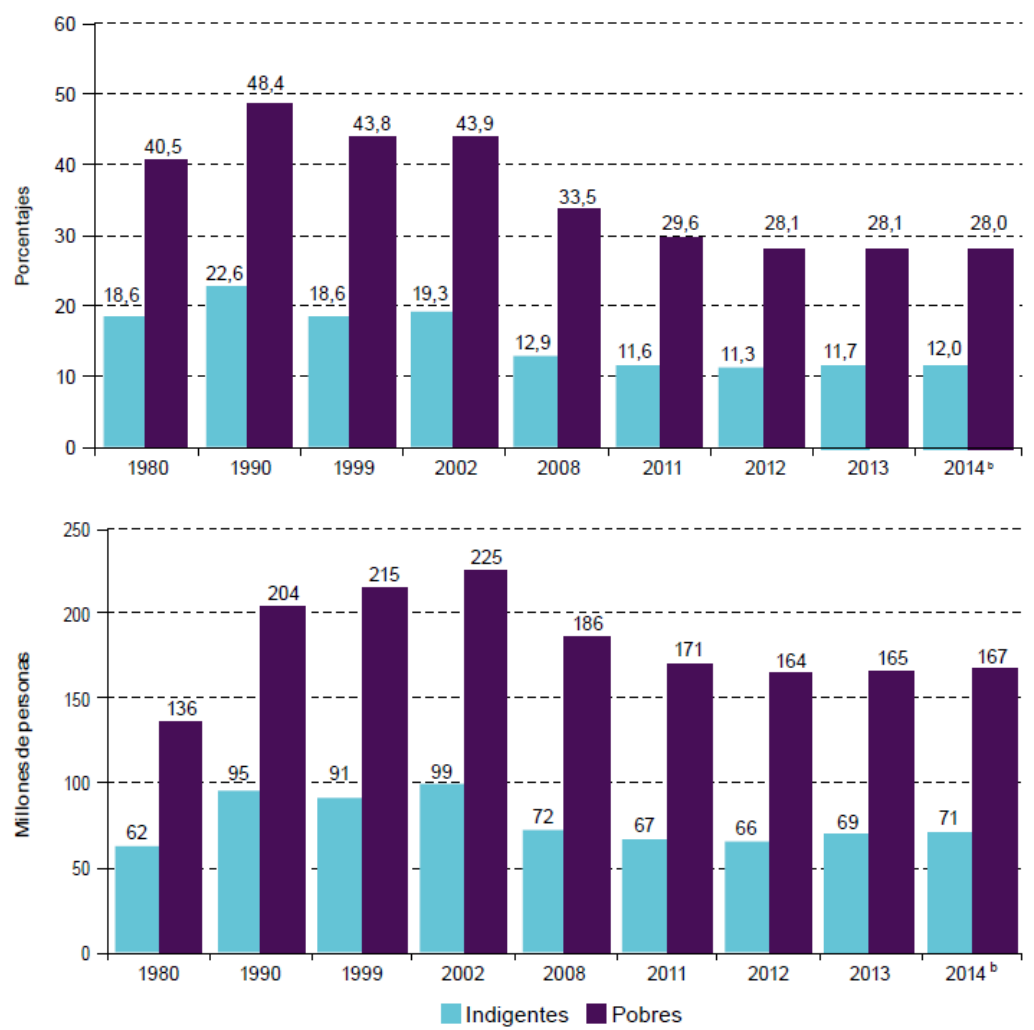

Fuente: Comisión Económica para América Latina y el Caribe (CEPAL), sobre la base de tabulaciones especiales de las encuestas de hogares de los respectivos países. a Estimación correspondiente a 19 países de América Latina, incluido Haití. No se incluye a Cuba.

b Proyección.

Admite-se, por hipótese, que, se a América Latina, sob a inspiração da ideia de integração, aproveitar as lições da crise de 2008, poderá até mesmo vislumbrar posição de certo relevo na economia mundial. Para alcançar esse objetivo, a construção de consensos e o somatório de esforços entre os países da região pode, a médio prazo constituir uma estratégia que permita à América Latina galgar uma posição de destaque na economia mundial. É certo que a presença de governantes com visão estadista e possuidores de talento político sobressai como uma condição importante para a instauração de novo paradigma de integração regional. A pertinência de uma visão mais altaneira da ideia de integração, deriva do fato, conforme alertou Alicia Bárcena, Secretária Executiva da Cepal (Comissão Econômica para a América Latina e o Caribe), de a América Latina e o Caribe se encontrarem hoje numa encruzilhada. Com diferentes velocidades, mas considerando a acentuada heterogeneidade entre os países, foram alcançados nos últimos anos, como já mencionado, progressos significativos em relação à redução da pobreza, do desemprego e de outros indicadores. A crise de Wall Street de 2008 colocou em evidência um novo cenário econômico marcado por restrições e incertezas. A partir dessa crise, instaurou-se ritmo mais lento e instável do crescimento que atingiu tanto os países mais industrializados como os emergentes. Diante desse quadro,

\begin{tabular}{l|l|l|l|l|l} 
(c) Revista Triangulo & Uberaba, Minas Gerais & v.11 & n.4 - Esp & p. 7-26 & 2018
\end{tabular}


sobressaem os dilemas entre soluções de extrema austeridade e ajuste fiscal ou soluções de inspiração keynesiana (BÁRCENA, 2014, p. 13).

\section{Contexto cultural: as ideias de Miguel Rojas Mix}

Se por um lado, se evidencia a importância das questões sociais e econômicas, por outro, os desafios culturais e étnicos são igualmente relevantes. Nessa dimensão, ao longo da história da América Latina, não faltaram vozes em defesa de um continente mais integrado e solidário. Como observou com propriedade Rojas Mix, proeminente pensador chileno dos desafios latino-americanos, desde Andrès Bello, la mayoria de los intelectuales latinoamericanos ha considerado una tarea principal terminar con el colonialismo mental. Dos aspectos reproducen este colonialismo: la incapacidad de constituir el pensamiento en referencia, y su secuela: la reflexión mediatizada (MIX, 2004, p. 433). Porém, pondera Mix (p. 434): No es que haya un vacío de teoría, como aseguran algunos: no habrá pensamiento americano mientras nosotros mismos no seamos capaces de valorizarlo y convertirlo en referencia. No se trata de dar la espalda al pensamiento llamado universal. Todo es cuestión de preposiciones. Debemos servirnos 'de', pero no servir 'a'. Hemos visto a lo largo de nuestra reflexión, continua Mix, que los mayores mitos y las más grandes incertidumbres de identidad proceden de atribuir 'autoridad' a un intelecto extraño.

As ideias de Rojas Mix (2004, p. 31) sobre a América Latina se apoiam em alguns pressupostos fundantes que estão enraizados na história do continente, que ele denomina los cuatro abuelos. Quatro abuelos compõem as raízes da América Latina: o índio, o negro, o espanhol e o imigrante. E certamente haverá de ser acrescentado um quinto que é o português. Eles estão sempre presentes na nossa sociedade, na nossa cultura e na nossa identidade. Todavia, o processo de colonização silenciou as vozes do índio e do negro. Rompeu com suas identidades. Como afirmou Mix, solo los nuevos rostros podian hablar de Dios (p. 35). Com a independência, os paradoxos contraditoriamente se agravaram: exemplificando, os Guaranis foram repartidos entre Paraguai, Argentina e Brasil; os Aymarás entre Bolívia, Peru e Chile; os Mapuches entre Chile e Argentina e assim por diante. Reconocidas las nuevas tierras como indias, los conquistadores que seguieran al navegante obligaron a los naturales a llamarse indios. Así dejaron de ser abipón, aymará, apache, azteca, cayeté, tapuya, tolteca (...) (p. 35). Madres, padres e hijos son dispersados a los cuatro vientos. El negro no tiene más familia que su amo. Solo a escondidas puede seguir practicando sus cultos (p. 39).

\begin{tabular}{l|l|l|l|r} 
C Revista Triangulo & Uberaba, Minas Gerais & v.11 & n.4-Esp & p. 7-26
\end{tabular}


São valiosas as reflexões de Miguel Rojas Mix para a ideia de cooperação integrada e solidária entre os países pertencentes à Unasul. A América Latina, em que pesem suas grandes assimetrias e diferenças regionais, logrou ao longo de sua história, produzir um acervo de conhecimentos e de reflexões de nível universal, que precisa ser valorizado e convertido em referência. Por isso, importa reconhecer que é pela integração, ou seja, pelo somatório de esforços e pelo conhecimento das diferenças, fundamentados nos princípios de cooperação solidária e reciprocidade, que a América Latina e o Caribe terão condições de alcançar estágios civilizatórios caracterizados por mais justiça e equidade. Para tanto, sobressai o papel da educação e de redes de conhecimento, que se definem como insubstituíveis sob todos os aspectos. Não uma educação que ignore as raízes da formação histórica das várias nações latino-americanas. Como observou Mix, lo que buscamos en el pasado es lo que permite construir ese futuro. Solo asi la utopía puede ser una "utopía concreta”. Por eso, las raíces de la identidad están en el futuro (2004, p. 436).

Nessa direção de raciocínio, cresce a indissociabilidade entre educação e cultura. $\mathrm{Na}$ teoria e na prática estão imbricadas, pois como chamou atenção Morais, a trajetória de uma cultura é a própria historicidade do povo que a vive. Somos o resultado e o cumprimento de uma história. Desse modo, numa filosofia da educação é a realidade educacional que interroga a filosofia, solicitando suas contribuições para a elucidação do sentido do educar. Trata-se, em verdade, de um diálogo que só tem sentido na ambiência do pano de fundo de uma filosofia da cultura (MORAIS, 1989, p. 187).

Se é da realidade que devemos partir, ainda que se considere a variedade polissêmica desse vocábulo, não podemos imaginar uma política de educação, cultura e ciência, que deixe à margem símbolos e significados que foram se delineando ao longo da história de um país. E, no caso da América Latina, como se tem procurado mostrar ao longo deste texto, só nos últimos decênios, os países do continente começaram a ter consciência mais clara de suas perdas de identidade devido à política colonial de destruição das raízes, isto é, das "realidades mais profundas" de cada país. Na linha desses pressupostos, os fundamentos culturais da educação e da pedagogia elevam-se ao status de uma das matrizes que devem ocupar posição de destaque nos projetos de desenvolvimento de cada nação, especialmente no campo da concepção e formulação de políticas de educação, cultura, ciência e tecnologia.

É nessa linha de raciocínio que o futuro depende da educação. Uma educação que, não ignorando o que foi o passado colonialista, possa, a partir das contribuições e dimensões 
humanas das raízes, projetar e preparar mentes para cenários que tenham em sua centralidade a preocupação com o bem-estar das pessoas. Por isso, afirma Mix (2004, p. 437), la integración no es una utopía, sino una urgencia, pois por seu intermédio, as energias criadoras se ampliam e a ideia de compartilhamento possa se edificar como um valor insubstituível em tempos de incertezas.

Miguel Mix, valendo-se de uma reflexão de Ortega y Gasset de que a vida humana é um gerúndio, afirmou que la identidad, como la vida, es un gerundio, un continuo hacerse del ser (MIX, 2004, p. 32). Desse modo, com a consciência de suas origens, a América Latina e o Caribe estão em processo de ser, de instituir um novo cenário civilizatório multicultural e, por conseguinte, mais democrático. Também o pensamento de Darcy Ribeiro desdobra-se nessa linha. Em seu admirável ensaio sobre o povo brasileiro, ele não teve dúvidas em dizer: “(...) somos um povo em ser, impedido de sê-lo. Um povo mestiço na carne e no espírito, já que aqui a mestiçagem jamais foi um crime ou pecado. Nela fomos feitos e ainda continuamos nos fazendo (...). Um povo hoje, em ser, na dura busca de seu destino" (RIBEIRO,1995, p. 447). A consciência de "estar sendo" cujos novos avanços se mostram mais à vista, pode ter na política de educação e produção de conhecimentos, devidamente contextualizada, e com vistas ao futuro, conforme sugeriu Miguel Mix, um poderoso aliado.

Conceber políticas de educação e conhecimento considerando o contexto e os pressupostos culturais que se legitimaram ao longo da história de uma região ou de um país, estabelece-se como condição necessária para garantir a legitimidade identitária dessas políticas. A educação, na clássica conceituação de Emile Durkheim, isto é, de transmissão das maneiras de ser, pensar, agir e sentir das gerações mais velhas às gerações mais jovens, supõe a consideração pelos valores culturais. Por isso, é imperioso lembrar que mesmo com o avassalador processo de homogeneização provocada pelo capitalismo, os laços culturais não se desfizeram. Como bem acentuou Maybury-Lewis:

\begin{abstract}
A globalização da economia mundial, a internacionalização dos processos e instituições, de bancos, negócios e até de empregos do qual todos dependemos, parecem ir de par com os sentimentos agudos de nacionalismo e com a intensificação dos conflitos étnicos. Quando se podia argumentar, de maneira confiável, que a questão étnica estava fadada a desaparecer, fazia certo sentido ignorá-la ou suprimi-la. Agora, esses argumentos provaram ser insustentáveis, e o mundo acordou para o fato de que não é possível ignorar ou negar a questão étnica. (2001, p. 90-91).
\end{abstract}

E acrescenta o professor e pesquisador da Universidade de Harvard: 
Os indígenas americanos constituem um exemplo clássico desse tipo de etnicidade. $\mathrm{Na}$ época da invasão das Américas pelos europeus, esses povos, como os próprios povos da Europa, estavam divididos em uma multiplicidade de grupos separados. Foram os invasores que os chamaram de "índios", de acordo com a famosa confusão de Cristóvão Colombo. Desde então, cada nação americana tem sistematicamente colocado em um mesmo grupo os "autóctones" como índios, desenvolvendo políticas para seus "índios", e assim por diante, com o resultado de que os próprios povos indígenas têm sido levados a agir em conjunto como "índios", a fím de defender seus próprios interesses. (MAYBURY-LEWIS, 2001, p. 92).

Análise semelhante pode ser feita também em relação aos negros do continente americano. Com relação a estes, nunca será demais repetir que, embora possua o Brasil a maior população negra das Américas, eles estão presentes também em vários países. Gates Júnior, que estudou as relações raciais em seis países da América Latina e Caribe, respectivamente, Brasil, México, Peru, República Dominicana, Haiti e Cuba, afirmou, com base no banco de dados dos historiadores David Eltis e David Richardson, que entre os anos de 1502 e 1866, 11,2 milhões de africanos sobreviveram à terrível travessia oceânica e chegaram como escravos ao Novo Mundo. Desse total, somente 450 mil desembarcaram nos Estados Unidos, sendo que 4,8 milhões foram para o Brasil (GATES JÚNIOR, 2014, p. 15), e o restante para outros países da América Latina e Caribe. A propósito da questão negra, creio ser oportuno sublinhar o argumento de Mbembe, no sentido de que para construirmos um novo humanismo, "para construir este mundo que é o nosso, será necessário restituir, àqueles e àquelas que passaram por processos de abstracção e de coisificação na história, a parte da humanidade que lhes foi roubada"(MBEMBE, 2017, p.304).

Os negros, como os índios, também travam uma batalha pela inclusão, o que significa que os movimentos sociais em prol da plena igualdade dos afrodescendentes se ampliarão e se afirmarão em todas as Américas, de forma a garantir que os descendentes de milhões de negros que em séculos anteriores aqui chegaram, tenham os seus direitos reconhecidos (GATES JÚNIOR, 1014, p. 307) e passem a vislumbrar a possibilidade de conviver em cenários sociais de igualdade e reciprocidade. Com fundamento nessa hipótese, sobreleva o papel da escola, como um dos fatores cruciais para a efetivação dos direitos humanos. Certamente, a progressiva universalização da educação básica, incluindo o respeito à diversidade cultural como um dos critérios para a avaliação da qualidade, poderá proporcionar a instauração de políticas educacionais que possam de fato ajudar a fazer do processo educativo fator valioso para o avanço da igualdade.

Para esse fim, o papel do Estado é insubstituível. Não o Estado mínimo prisioneiro das ideias liberais e insensível à vida das pessoas, mas um Estado-nação revigorado e capaz de 
engendrar o indispensável equilíbrio entre Estado Liberal e Estado Social. Conforme os estudos de Maybury-Lewis,

[...] a Europa Ocidental produziu a moderna ideia do Estado, mas é hoje claro que os Estados dessa parte do mundo não realizaram as esperanças dos racionalistas que escreveram na época da Revolução Francesa. Estes esperavam que os Estados do futuro fossem informados por valores liberais, e que neles os cidadãos interagiriam em bases iguais (2001, p. 93).

Todavia, o que de fato aconteceu nos países americanos foi a exclusão dos índios e dos negros do direito à cidadania. Maybury-Lewis acredita que o desenvolvimento da teoria sobre Estados multiétnicos constituirá um passo necessário se mantivermos a esperança de mudar o pensamento predominante no Ocidente (2001, p. 100). É preciso considerar, no entanto, que a mudança de pensamento defendida por Maybury-Lewis depende da possibilidade de uma ética global. A questão principal, sugere Lourdes Arizpe, é saber se o aprimoramento das tecnologias da comunicação e informação mundiais intensificará a criação em escala global de normas éticas e instituições verdadeiramente universais, ou se serão empregadas de forma míope apenas para favorecer interesses de determinados grupos ou países (ARIZPE, 2001, p. 111). Trata-se de uma questão complexa e inadiável. A crise econômica de 2008 deixou várias lições, entre elas, a urgência de pensar caminhos alternativos viáveis, daí decorrendo o papel da Universidade como instância que tem condições para produzir reflexões e conhecimentos para subsidiar a construção de cenários emancipadores e pautados por princípios de justiça e maior igualdade.

\section{O papel da Universidade}

Desde os brados da juventude de Córdoba de 1918 que ecoam continente afora por quase um século, os compromissos com a autonomia, a liberdade, a integração, a ética e a dimensão humana da universidade na América Latina... Ecos que se ampliaram anos após anos, em conferências e eventos regionais e internacionais, convergindo para a ideia de uma universidade voltada para o bem-comum do continente... Ecos que se converteram em ações e repetidamente proclamados em declarações públicas elaboradas e aprovadas por dirigentes e estudiosos da universidade na América Latina... Foi assim, na Conferência de Havana, de 1996, como também na Conferência de Cartagena de Índias, em 2008, ambas organizadas pela Unesco, e no Fórum Latino-Americano de Educação Superior, realizado em Foz do 
Iguaçu, estado do Paraná, em 2014. A Declaração de Havana, recordando Córdoba, além de afirmar que este fato tenha ocorrido para dar respostas a uma sociedade muito diferente da atual, destacou-se por impulsionar um movimento de democratização universitária, insistindo na implantação de vínculos sólidos entre a ação das universidades e as exigências da sociedade. Reconheceu que o conhecimento é um bem social público que só pode ser produzido e utilizado em benefício da sociedade. Por isso, a educação superior deve fortalecer sua capacidade de análise crítica, de antecipação e de visão prospectiva, devendo incentivar a formação de mentes com a consciência de pertencer à comunidade de nações da América Latina e do Caribe, promovendo processos que conduzam à integração regional, situando a integração cultural e educativa como base da integração política e econômica. A Declaração de Cartagena começa por sublinhar que a educação superior é um bem público social, um direito humano e universal e um dever do Estado. Esta é a convicção e a base para o papel estratégico que deve assumir nos processos de desenvolvimento sustentável dos países da região. Declara que região é marcadamente pluricultural e multilíngue. A integração regional e a abordagem dos desafios que enfrentam nossos povos requerem enfoques próprios que valorizem a diversidade humana e natural da região. A educação superior como bem público social enfrenta correntes que promovem sua mercantilização e privatização, assim como a redução do apoio e financiamento do Estado. É fundamental reverter esta tendência. A educação superior tem um papel imprescindível na superação das discrepâncias científicas e tecnológicas atuais em relação a países mais desenvolvidos e no interior da região. Para tanto, torna-se necessário a construção de uma agenda em ciência, tecnologia e inovação compartilhada pela universidade latino-americana e caribenha com o objetivo de gerar o conhecimento que os povos da região demandam. Por sua vez, a Declaração de Foz do Iguaçu, considerando o contexto mundial composto por espaços econômicos integrados e altamente competitivos, mostra que também na América Latina é importante a integração regional como alternativa necessária para redimensionar e potenciar as unidades nacionais integradas. Nesse sentido, a construção do Espaço Latino-Americano e Caribenho de Educação Superior (Enlaces) deve ser entendido como uma plataforma regional de conhecimento e integração. Nesse cenário, a cooperação internacional e regional, tanto SulNorte quanto Sul-Sul, constitui uma necessidade impostergável. Em decorrência, a internacionalização da educação superior deve ter por princípio a cooperação solidária e a partilha de conhecimentos e saberes. 


\section{Redes de Conhecimento}

A Declaração de Cartagena acentuou a importância das redes acadêmicas como estratégia privilegiada para o avanço da construção solidária do conhecimento. A história e os avanços construídos no âmbito da cooperação, afirma a Declaração, têm transformado nossas Instituições de Educação Superior em atores com vocação de integração regional. Mediante a constituição de redes, as Instituições de Educação Superior da região podem unir e compartilhar o potencial científico e cultural que possuem para analisar e solucionar problemas estratégicos. Tais problemas não reconhecem fronteiras e sua solução depende da realização de esforços conjuntos das Instituições de Educação Superior e dos Estados. As redes acadêmicas, em escala nacional e regional, são interlocutores estratégicos perante os governos. São, também, os protagonistas indicados para articular de maneira significativa identidades locais e regionais, colaborando ativamente na superação das fortes assimetrias que prevalecem na região e no mundo, face ao fenômeno global da internacionalização da educação superior. Acrescente-se que na história da cultura humana, as universidades e demais instituições de pesquisa, em que pesem muitas críticas que lhes são dirigidas, sobressaem como as mais éticas, com quase 1000 anos de existência de trabalho em prol da revelação de talentos, construção de conhecimentos e formação de novas mentes. Desse modo, uma comunidade acadêmica trabalhando em rede, norteada pelos princípios e diretrizes que serviram de fundamento para a Declaração de Budapeste sobre o uso ético do conhecimento científico, constitui no cenário atual, estratégia de inegável alcance para assegurar que os frutos das melhores inteligências que estão nas universidades possam ser colocados de fato em favor da igualdade social e da melhoria de vida de todas as pessoas.

\section{Perspectivas}

$\mathrm{Na}$ linha de argumentos do presente texto, pode-se afirmar que as redes de conhecimento apontam em direção a cenários mais promissores. No caso da América Latina, a experiência da Rede de Estudos sobre Internacionalização da Educação Superior na América Latina (Riesal), tão bem analisada por Maria Soledad Oregione e Fernando Julio Piñero (2016), mostrou o alcance e a importância das redes acadêmicas. Também a experiência das Cátedras Unesco (rede Unitwin) criadas por Marco Antonio Dias logo após a 
Conferência de 1998 que resultou na Declaração Mundial para a Educação Superior no Século XXI, hoje espalhadas pelos vários continentes, configura-se como um caminho que vem apresentando resultados promissores. É certo que nem todas as Cátedras funcionam conforme as expectativas iniciais. Todavia, muitas delas operam em rede, No caso da América Latina, a experiência da Rede de Estudos sobre Internacionalização da Educação Superior na América Latina (Riesal), tão bem analisada por Maria Soledad Oregione e Fernando Julio Piñero (2016), mostrou o alcance e a importância das redes acadêmicas. As Cátedras Unesco foram instituídas no contexto da Declaração Mundial de 1998, ou seja, da Universidade como um bem social comum acima de quaisquer outros interesses ou concepções reducionistas. Além disso, sobressai como perspectiva na esteira da integração regional, um expressivo número de projetos conjuntos de pesquisas, em todas as áreas do conhecimento, que estão em curso na América Latina, financiados com base em acordos multilaterais e bilaterais por agências e órgãos de financiamento à pesquisa de vários países do continente. No caso do Brasil, agências como a Capes, CNPq, Fapesp e várias outras estão financiando projetos dos quais participam pesquisadores de vários países da região. A expansão dessa política potencializada por redes de conhecimento poderá ampliar políticas de integração e a construção mesmo de uma ideia de América Latina, da mesma forma como existe uma ideia da Europa. Segundo J. Guéhenno, o espírito europeu é uma certa esperança de liberdade e de justiça, que é o produto de todo um trabalho que se processa em nós, depois de ter sido processado no século XIX (GUÉHENNO, 1962, p. 65). Também nós podemos imaginar a consciência de um espírito latino-americano. As nossas línguas já começaram a ser ensinadas e caminham para o bilinguismo. Em tempos mais recentes, os nossos pesquisadores e estudantes começaram a impulsionar a mobilidade regional, a exemplo do Projeto Marca, que tantas oportunidades já criou para a circulação, intercâmbio e diálogo entre mentes e inteligências oriundas de vários países.

Por último, conforme salientam Oregioni e Piñero (2017), torna-se necessário pensarmos um processo de internacionalização pelas redes por intermédio de práticas não hegemônicas que se transformam em contra-hegemônicas na medida em que encontram instrumentos para a ação. Por isso, sublinha Marco Antonio Dias, no mundo atual é necessário contar com um marco conceitual adotado por consenso para definir os princípios a serem seguidos pelas políticas de educação superior, um marco ancorado num novo conceito de globalização que não pode seguir sendo definido por organizações como o Bird, o Fami ou 
a OMC (DIAS, 2017, p. 86). Daí ser preciso, como afirma Miguel Mix, pensar a globalização em termos latino-americanos (MIX, 2008, p. 214).

\section{REFERÊNCIAS}

ARIZPE, L. (Org.). As dimensões culturais da transformação global. Brasília: Unesco, 2001 .

BÁRCENA, A. Prólogo ao documento: CEPAL. Pactos para la igualdad. Santiago, 2014.

CASTRO, M. L. O. Relações entre o Legislativo e o Executivo nas reformas educacionais no Brasil, na Argentina e no México (1990-2010). Tese de Doutoramento. Brasília: UnB, 2012.

CUNHA, C. da. Estudo comparativo dos sistemas educacionais dos países da Unasul. Caracas: Unasul, 2016.

CROSSLEY, M. Repensando o contexto em educação comparada. In: COWEN, R.; KAZAMIAS, A. M.; UNTERHALTER, E. (Orgs.). Educação comparada: panorama internacional e perspectivas. v. 2. Brasília: Unesco-Capes, 2012. p. 628-646.

DIAS, M. A. R. Enseñanza superior como bien público. Montevideo: AUGM, 2017.

GATES JR., H. L. Os negros na América Latina. São Paulo: Cia. das Letras, 2014.

GUÉHENNO, J. Primeiro debate. In: BENDA, J. et al. O espírito europeu. Lisboa: EuropaAmérica, 1962.

GUIDDENS, A. Sociologia. 4. ed. Porto Alegre: Artmed, 2001.

MAYBURY-LEWIS, D. Convivendo com a questão étnica: a necessidade de um novo paradigma. In: ARIZPE, L. As dimensões culturais da transformação global. Brasília: Unesco, 2001. p. 89-103.

MBEMBE. A. Crítica da razão negra. $2^{\mathrm{a}}$.ed. LISBOA: Antígona, 2017.

MEHTA, S. Pequenas e grandes histórias: para além de teorias em disputa, rumo ao multiálogo. In: COWEN, R.; KAZAMIAS, A. M.; UNTERHALTER, E. (Orgs.). Educação comparada: panorama internacional e perspectivas. Brasília: Unesco-Capes, 2012.

MIX, M. Los cien nombres de América. Córdoba: UNC, 2004.

Alma Mater: la universidad latinoamericana: perspectivas y compromisos para el siglo XXI. Entre Ríos: Editorial de la Universidad Nacional de Entre Ríos, 2008.

MORAIS, R. de. Cultura brasileira e educação. Campinas: Papirus, 1989. 
OREGIONI, M. S.; PIÑERO, F. J. Las redes como estrategia de internacionalización universitaria en Mercosur: el caso de la Riesal. In: Revista Integração e Conhecimento, n. 4/2016. Córdoba: Neies-Mercosul, 2016.

PAULINO, L. A.; PIRES, M. C. A título de conclusão: as perspectivas da América Latina no limiar do século XXI. In: MENDONÇA, M. G.; PIRES, M. C. Formação econômica da América Latina. São Paulo: LCTE, 2012.

RIBEIRO, D. O povo brasileiro. São Paulo: Cia. das Letras, 1995.

SADLER, M. How for can we learn anything of practical value In: HANS, N. Educação comparada. S.Paulo: Editora Nacional, 1997.

SEN, A. Desenvolvimento como liberdade. S.Paulo: Companhia das Letras, 2000.

SODRÉ, N. W. Ideologia do colonialismo. Rio de Janeiro: Civilização Brasileira, 1965.

UNESCO. Declaração de Cartagena. Cartagena, 2008. Mimeo.

UNESCO. Declaração de Budapeste. In: Ciência para o século XXI. Brasília: UnescoAbipti, 2003.

UNESCO. Declaração de Havana. In: Werthein, J.; CUNHA, C. Fundamentos da educação para o século XXI. Brasília: Unesco, 2000. 